\section{Playing with science}

\section{Robert Marc Friedman}

\author{
Science on Stage: From Doctor Faustus \\ to Copenhagen \\ by Kirsten Shepherd-Barr \\ Princeton University Press, Princeton, \\ NJ, USA \\ 264 pp, \$30/£19 \\ ISBN 9780691121505
}

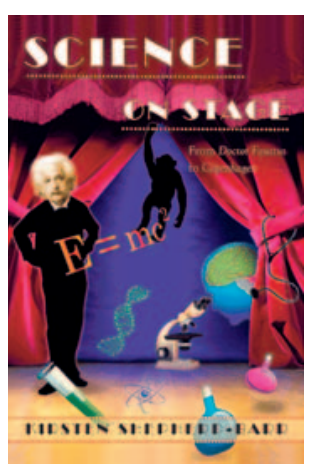

Science, under various guises, features in several recent wellpublicized plays. After the critical and commercial success of Michael Frayn's Copenhagen (1998), doors seemed to open for plays featur-

ing science. Furthermore, research foundations have begun teaming up with theatres to spawn new 'science plays'. Arts' journalists have called attention to an alleged new trend in the making. Something is happening, but what and why?

Science on Stage: From Doctor Faustus to Copenhagen purports to be a scholarly survey of the place of science in theatre, from the Renaissance to the present. Publicized as the first full-length study of this topic, the book invites some comment. Although often brimming with author Kirsten Shepherd-Barr's enthusiasm, the book gallops through much material but ultimately goes nowhere. Shepherd-Barr, a senior lecturer in theatre arts at Birmingham University, UK, is stuck riding an overly academic hobby-horse. For a work that celebrates - to the point of overstatement - the bridging of science and the arts, it disappointingly inhibits dialogue by adopting a parochial theoretical perspective that tends to be dismissive of all those who have refused baptism in the postmodernist faith.

Both publisher and author attempt to surf the crest of a wave that might not be quite as formidable or unique as we are asked to believe. While providing glimpses into the history of plays in which science or scientists appear, Shepherd-Barr asserts that during the past decade "a surge of new plays about science has created a new phenomenon." She hails the theatre as uniquely able to bridge the gap between C. P. Snow's legendary two cultures and goes one step further to claim that the best of the science plays are generating new innovative forms of theatrical experience. As much as I would like to embrace these declarations, I find her evidence unconvincing.

Are theatres bubbling over with plays dealing with science? Apart from academic theatre-studies journals, has science, in any shape or form, entered more forcefully into the mental landscape of playgoers and playmakers? Although Shepherd-Barr defines science broadly, including medicine and technology, her search for proof of the alleged flourishing state of affairs is confusing. Is it sufficient if characters just happen to be biologists or mathematicians? What is the cultural significance of a playwright using scientific concepts as a metaphor? She concedes that some plays discussed at length actually provide minimal insight into science.

What does it mean to facilitate communication between the two cultures, and on whose terms? Although often evoking Snow, the book is innocent of the much longer histories of mutual ignorance and hostility between natural scientists and humanists, as well as of how artists in differing historical contexts have responded to science. Without such intellectual ballast, ShepherdBarr provides little more than a catalogue of past plays and themes; and one that is biased towards the English language.

More importantly, why the recent flurry of activity and interest in science plays? Why now, and why the theatre as a privileged forum? The book offers minimal insight into contextual issues that might be useful for understanding the surge of science on stage. How might post-Cold War adjustments in scientific communities be relevant? A sense of crisis provoked many scientists to reflect on professional identity, and to promote science as culture and as a source of economic competitiveness. Individuals and institutions launched initiatives to assist the public understanding of science and to attract young people to science. These encouraged a wide range of interactions between science and the arts, some fun and frivolous, others provoking reflection and even outraged debate. We also need greater insight into the realities of producing plays; what, if anything, changed in recent decades?

It seems disingenuous to look to theatre as a cure for the two-culture blues while ignoring how other performing, visual and literary arts mediate and use science. Shepherd-Barr dismisses film as a viable medium, other than in documentary form. And yet, television dramatization-not mentioned at all-has proven able to produce films that both entertain and educate. BBC's The Race for the Double Helix and Canadian Broadcasting Corporation's Glory Enough for All immediately come to mind.

Shepherd-Barr waxes enthusiastic about plays that conform to academic discussions of so-called performability, in which form and content merge, and about highly innovative isolated experiments that focus on concepts, such as infinity, but has little to say about Carl Djerassi's many plays, which have enjoyed massive interest and numerous performances. That one of the world's leading chemists has turned to drama for communicating insights about science surely deserves attention. I was amused to find my one-act play Remembering Miss Meitner discussed briefly, but ShepherdBarr does not seem to have understood what the play is about or how it works on stage. She is dismissive of my anxiety over harmonizing historical scholarship with dramatic art. True, I believe authors have intentions and ethical responsibilities, which hopefully will be respected during production. Although of little interest as fodder for her agenda, this prize-winning play has sparked post-performance discussions, earned critical praise in the media and generated extraordinary enthusiasm. As it is critical of the Nobel institution and the erosion of collegial morality in science, the play prompted debate and some underhanded responses-but in the end, dialogue and mutual respect came to the fore. Theatre can open communication between cultures, but in ways more profound than Shepherd-Barr allows.

Some readers might wonder why I sound a bit curmudgeonly. After all, it's only theatre; just as some literary-studies folks might say, "hey, it's only science." Call me oldfashioned, but in an age in which media and even academia trivializes almost everything, I would like to think that both the creative arts and the sciences deserve better.

\footnotetext{
Robert Marc Friedman is professor of history of science at the University of Oslo, Norway. His most recent drama, Becoming Albert Einstein, enjoyed professional stage performances in Bergen and Oslo. E-mail: robert.friedman@iakh.uio.no doi:10.1038/sj.embor.7400971
} 